Canadian

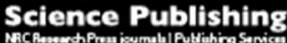

Biochemistry and Cell Biology

Biochimie et biologie cellulaire

\title{
Characterization of a Salmonella sugar kinase essential for utilization of fructose-asparagine
}

\begin{tabular}{|r|l|}
\hline Journal: & Biochemistry and Cell Biology \\
\hline Manuscript ID & bcb-2016-0138.R1 \\
\hline Manuscript Type: & Note \\
\hline Date Submitted by the Author: & 27-Jul-2016 \\
\hline Complete List of Authors: & $\begin{array}{l}\text { Biswas, Pradip; The Ohio State University, Chemistry \& Biochemistry } \\
\text { Behrman, Edward; The Ohio State University, Chemistry \& Biochemistry } \\
\text { Gopalan, Venkat; The Ohio State University, Chemistry \& Biochemistry }\end{array}$ \\
\hline Keyword: & $\begin{array}{l}\text { Salmonella, Fructose-asparagine, Fructose-aspartate, Kinase, 6- } \\
\text { Phosphofructose-Aspartate }\end{array}$ \\
\hline \multicolumn{2}{|c}{} \\
\hline
\end{tabular}

\section{SCHOLARONE}

Manuscripts 


\title{
Characterization of a Salmonella sugar kinase essential for utilization of fructose-asparagine
}

\author{
Pradip K. Biswas, Edward J. Behrman* and Venkat Gopalan* \\ Department of Chemistry \& Biochemistry, \\ The Ohio State University, Columbus, OH 43210, USA
}

Correspondence: behrman.1@osu.edu or gopalan.5@osu.edu

Keywords: Salmonella, Fructose-Asparagine, Fructose-Aspartate, 6-Phosphofructose-Aspartate, Kinase 


\section{Abstract}

Salmonella can utilize fructose-asparagine (F-Asn), a naturally occurring Amadori product, as its sole carbon and nitrogen source. Conversion of F-Asn to the common intermediates glucose-6phosphate, aspartate, and ammonia was predicted to involve the sequential action of an asparaginase, a kinase and a deglycase. Mutants lacking the deglycase are highly attenuated in mouse models of intestinal inflammation due to the toxic build-up of the deglycase substrate. The limited distribution of this metabolic pathway in the animal gut microbiome raises the prospects for antibacterial discovery. We report the biochemical characterization of the kinase that was expected to transform fructose-aspartate to 6-phosphofructose-aspartate during F-Asn utilization. In addition to confirming its anticipated function, we determined through studies of fructose-aspartate analogues that this kinase exhibits a substrate-specificity with greater tolerance to changes to the amino acid (including the D-isomer of aspartate) than to the sugar. 


\section{Introduction}

D-Fructose-L-asparagine (F-Asn) is an Amadori rearrangement product (Mossine and Mawhinney 2010) that occurs naturally in substantial quantities in foods, particularly after heating (Anet and Reynolds 1957; Eichner et al. 1994). Salmonella enterica serovar Typhimurium can utilize F-Asn as its sole carbon and nitrogen source (Ali et al. 2014; SabagDaigle et al. 2016). The fra locus in Salmonella is required for F-Asn utilization and consists of a gene encoding a transcriptional repressor (FraR) and the fraBDAE operon, which encodes a deglycase (FraB), kinase (FraD), transporter (FraA) and asparaginase (FraE). The functional roles for the structural genes in this operon were proposed based on the well-established pathway in Escherichia coli for utilization of D-fructose-L-lysine (F-Lys), another Amadori product (Wiame et al. 2002). Conversion of F-Asn to the common metabolic intermediates Dglucose-6-phosphate, L-aspartate and $\mathrm{NH}_{4}{ }^{+}$was predicted to occur in three steps (Fig. 1).

Mutations in the fraB gene cause a severe attenuation in mouse models of inflammation (Ali et al. 2014). We recently showed that the fraB mutant accumulates the deglycase substrate (6phosphofructose aspartate), and suggested that the toxicity associated with this sugarphosphate buildup accounts for the attenuation in mice (Sabag-Daigle et al. 2016). In addition to Salmonella, genes in the fra locus appear to be present only in Citrobacter and Clostridia, indicating a limited presence in the animal gut microbiome. These findings make fra $B$ an attractive target for future drug development, and motivate in-depth studies of the fra locus.

As part of our ongoing studies to characterize each of the gene products in the fra locus, we report here our investigations of the FraD kinase. Results from our experiments show that a recombinant FraD catalyzes the conversion of fructose-L-aspartate (F-Asp) to 6phosphofructose aspartate (6-P-F-Asp), and that it exhibits a substrate-specificity that is more tolerant of changes to the amino acid than to the sugar. 


\section{Materials and Methods}

Synthesis of Fructose-Aspartate and its analogues: Fructose-D-aspartate, fructose-L-glutamate, and tagatose-L-aspartate were made under the same conditions as those described for fructose-L-aspartate (Hansen and Behrman, 2016). Some modifications were required for the synthesis of fructose-L-cysteic acid, xylulose-L-aspartate and ribulose-L-aspartate. The fructose-L-cysteic acid reaction required longer heating: $17 \mathrm{~h}$ at $70^{\circ} \mathrm{C}$ followed by four more $\mathrm{h}$ at $80^{\circ} \mathrm{C}$. Furthermore, fructose-L-cysteic acid was bound so weakly to Dowex-50 that it was eluted in the first few fractions by water alone, reminiscent of the behavior of 6-phosphofructose-Laspartate (Hansen and Behrman 2016). The five carbon sugars, ribose and xylose, are much more reactive than glucose so that the reaction was carried out at $55^{\circ} \mathrm{C}$ for $16 \mathrm{~h}$. The greater reactivity of the pentoses was reported nearly a hundred years ago (Maillard 1912), and recent studies provide a quantitation of this increased reactivity (Katchalsky and Sharon 1953; Laroque et al 2008; Sun et al. 2006).

We established the identity and purity of each of the analogs of D-fructose-L-aspartate by several approaches. First, the identity was checked by measurement of the exact mass $[ \pm 0.001$ amu]. The MS spectra showed only trace amounts of the respective free amino acids. Second, proton NMR spectra gave the correct ratio of the upfield resonances due to the amino acid residue/the downfield resonances due to the sugar moiety and the $\alpha$-proton of the amino acid. Integration revealed that impurities are $<10 \%$. Third, consistent with the MS data, paper electrophoresis and TLC with ninhydrin-based detection showed only traces of the free amino acid. [It is characteristic that the free amino acid reacts more rapidly with ninhydrin as compared to the Amadori products.] Fourth, the IR spectra are typical of Amadori products (Hansen and Behrman, 2016) and confirm the absence of major impurities. Finally, the specific rotations of Dfructose-L-aspartate and D-fructose-D-aspartate are -72 (Hansen and Behrman, 2016) and -4.5 (this study), respectively. The specific rotations of many fructose-amino acids have been 
measured (Anet, 1957; Mossine et al. 1994; Walton et al. 1987). It is clear from these data that it is not possible to predict, even empirically, the rotations of the Amadori compounds based on those of the sugar and the amino acid components, although progress is being made in calculations for other compounds using density functional theory (Pardo et al. 2006). It suffices to say that the rotations of the diastereomeric D-fructose-aspartic acids are different.

Critical evidence for the absence of racemization during synthesis of D-fructose-D-aspartate came from the following observation: 6-Phospho-D-fructose-D-aspartate was made by heating D-glucose-6-phosphate with D-aspartate under the same conditions as those described for the synthesis of 6-phospho-D-fructose-L-aspartate (Hansen and Behrman, 2016). When this diastereomer was subjected to the action of a recombinant FraB, the deglycase in the F-Asn utilization pathway whose natural substrate is the L-aspartate diastereomer, the activity was 20fold lower showing that no racemization of the D-aspartate moiety had occurred (Sengupta, Thomsen, Behrman and Gopalan, unpublished data).

Overexpression and purification of FraD: The FraD-encoding ORF was amplified by PCR using as template Salmonella genomic DNA and cloned into pET-33b (Novagen) using the InFusion HD cloning kit (Clontech). This construct (pET-33b-HT-FraD), which was kindly provided to us by Drs. Anice Sabag-Daigle and Brian Ahmer (Ohio State University), was designed to express FraD with an $\mathrm{N}$-terminal $\mathrm{His}_{6}$-affinity tag followed by a tobacco etch virus (TEV) protease cleavage site (GluAsnLeuTyrPheGInSer).

E. coli Rosetta (DE3) cells were transformed with pET-33b-HT-FraD. A single colony was used to inoculate $5 \mathrm{ml}$ of LB medium containing $35 \mu \mathrm{g} / \mathrm{mL}$ kanamycin (Kan) and $35 \mu \mathrm{g} / \mathrm{mL}$ chloramphenicol (Cam), and grown overnight at $37^{\circ} \mathrm{C}$ with shaking. The overnight culture was used to inoculate $500 \mathrm{~mL}$ of LB medium supplemented with Kan and Cam (as above). The cells were grown at $37^{\circ} \mathrm{C}$ with shaking $(225 \mathrm{rpm})$ until $\mathrm{OD}_{600}$ reached $\sim 0.6$ at which time the culture 
was induced with $1 \mathrm{mM}$ isopropyl- $\beta$-D-thiogalactoside (IPTG). After IPTG addition, the cells were grown at $16^{\circ} \mathrm{C}$ for $20 \mathrm{~h}$ and harvested by centrifugation. The cell pellets were stored at $80^{\circ} \mathrm{C}$.

For purification of FraD, which entailed immobilized metal-affinity and ion-exchange chromatography in tandem, we used the following buffers: Buffer $\mathrm{A}-50 \mathrm{mM}$ Tris- $\mathrm{HCl}(\mathrm{pH} 7.5)$ and $500 \mathrm{mM} \mathrm{NaCl}$; buffer $\mathrm{B}$ - $50 \mathrm{mM}$ Tris-HCl pH- 7.5, $500 \mathrm{mM} \mathrm{NaCl}$ and $500 \mathrm{mM}$ imidazole; lysis buffer - 50 mM Tris-HCl (pH 7.5), 500 mM NaCl, 30 mM imidazole, 1 mM DTT, cOmplete mini-protease inhibitor cocktail tablet (Roche), $0.1 \mathrm{mM}$ phenyl methyl sulphonyl fluoride (PMSF), 40 U DNase I (Roche) and 0.5 mg/ml lysozyme (Boehringer Mannheim); buffer W - 50 mM Tris$\mathrm{HCl}(\mathrm{pH}$ 7.5), $500 \mathrm{mM} \mathrm{NaCl}, 1 \mathrm{mM}$ DTT and $0.1 \mathrm{mM} \mathrm{PMSF}$; buffer C - $50 \mathrm{mM}$ Tris-HCl (pH 7.5), $150 \mathrm{mM} \mathrm{NaCl}, 1 \mathrm{mM}$ DTT and 0.1 mM PMSF; buffer D - $20 \mathrm{mM}$ Tris-HCl (pH 7.5), $1 \mathrm{mM}$ DTT and $0.1 \mathrm{mM}$ PMSF; buffer $\mathrm{E}$ - $20 \mathrm{mM}$ Tris- $\mathrm{HCl}(\mathrm{pH}$ 7.5), $500 \mathrm{mM} \mathrm{NaCl}, 1 \mathrm{mM}$ DTT and $0.1 \mathrm{mM}$ PMSF; buffer F - 50 mM Tris-HCl (pH 7.5), 150 mM NaCl, $1 \mathrm{mM} \mathrm{DTT,} \mathrm{10 \%} \mathrm{(v/v)} \mathrm{glycerol} \mathrm{and}$ $0.1 \mathrm{mM}$ PMSF.

A cell pellet, obtained from a 500-mL overexpression culture, was thawed on ice, resuspended and sonicated in $25 \mathrm{~mL}$ of lysis buffer. After sonication, the crude lysate was centrifuged at $24,000 \mathrm{~g}$ for $40 \mathrm{~min}$ at $4^{\circ} \mathrm{C}$. The supernatant was collected and filtered through a $0.22 \mu \mathrm{m}$ syringe filter (Millipore) and applied to a 1-mL His-Trap HP column (GE Healthcare) that had been equilibrated with buffer W. After washing with $15 \mathrm{~mL}$ of buffer W, FraD was eluted using an AKTA FPLC (GE Healthcare) in three successive elution steps: 10-mL gradient from 50 to $250 \mathrm{mM}$ imidazole, $2.5-\mathrm{mL}$ gradient from 250 to $500 \mathrm{mM}$ imidazole and $2.5 \mathrm{~mL}$ of $500 \mathrm{mM}$ imidazole. FraD typically eluted between $\sim 130$ to $160 \mathrm{mM}$ imidazole. Using SDS-PAGE and Coomassie Blue staining, fractions containing predominantly FraD were identified and pooled. To remove the $\mathrm{His}_{6}$ tag, this pool was subjected to digestion with recombinant $\mathrm{His}_{6}$-TEV protease, which was purified as described before (Tropea et al. 2009). The TEV protease 
digestion (FraD:TEV, 20:1 molar ratio) was performed in a dialysis bag with one exchange against buffer $\mathrm{C}$ for $2 \mathrm{~h}$ at $30^{\circ} \mathrm{C}$ and then another overnight at $4^{\circ} \mathrm{C}$. The dialyzed reaction mixture was then incubated with 0.2-mL cOmplete His-Tag purification resin (Roche) to remove $\mathrm{His}_{6}-\mathrm{FraD}, \mathrm{His}_{6}$-tag (released from cleavage of $\mathrm{His}_{6}-\mathrm{FraD}$ ) and $\mathrm{His}_{6}-\mathrm{TEV}$ protease. The flowthrough, which was expected to contain FraD without the $\mathrm{His}_{6}$ tag, was subjected to MALDI-ToF mass spectrometry to confirm TEV cleavage, and then dialyzed overnight against Buffer D.

As a final polishing step, the dialyzed FraD preparation (above) was loaded onto a 1-mL QSepharose FF column (GE Healthcare) that been equilibrated with buffer D. After washing with $10 \mathrm{ml}$ of buffer $\mathrm{D}$, bound proteins were eluted using $10 \mathrm{~mL}$ of continuous gradient of buffer $\mathrm{D}$ and buffer $\mathrm{E}$ (0 to $500 \mathrm{mM} \mathrm{NaCl})$. FraD typically eluted at $\sim 200 \mathrm{mM} \mathrm{NaCl}$. Fractions containing FraD were identified using SDS-PAGE and Coomassie Blue staining, and those exhibiting near homogeneity were pooled and dialyzed against buffer $\mathrm{F}$ at $4^{\circ} \mathrm{C}$ overnight. After dialysis, the concentration of FraD was calculated using its molar extinction coefficient $\left(33,350 \mathrm{M}^{-1} \mathrm{~cm}^{-1}\right)$ and $A_{280}$ value. Aliquots of the final preparation were stored at $-80^{\circ} \mathrm{C}$ for later use.

FraD activity assays: FraD's kinase activity was assayed in a $40-\mu \mathrm{L}$ reaction mixture that contained 25 mM HEPES (pH 7.5), $25 \mathrm{mM} \mathrm{KCl,} 1 \mathrm{mM}$ DTT, $5 \mathrm{mM} \mathrm{MgCl}$, $1 \mathrm{mM} \mathrm{ATP,} 0.8 \mathrm{mM}$ fructose-L-aspartate, $0.1 \mathrm{mg} / \mathrm{mL}$ BSA and $10 \mathrm{nM} \mathrm{FraD} \mathrm{(or} \mathrm{as} \mathrm{indicated} \mathrm{in} \mathrm{the} \mathrm{text).} \mathrm{Purified}$ recombinant FraD was diluted in the assay buffer lacking the substrate and ATP. The standard assays were carried out at $37^{\circ} \mathrm{C}$ and at $\mathrm{pH} 7.5$ for $30 \mathrm{~min}$, with cleavage $<25 \%$ of the initial substrate concentration; to determine the $\mathrm{pH}$ and temperature optima, these parameters were varied as indicated. In all instances, blank reactions were set up using the same constituents except for the enzyme, and at the same $\mathrm{pH}$ and temperature as the test counterparts. The number of technical replicates for each experiment below is listed in the relevant section. 
Because one of our objectives was to measure the FraD kinase activity with various substrate analogs of F-Asp, we chose a detection method that focused on ADP, a common product regardless of the Amadori substrate used in the assay. The ADP-Glo Kinase assay kit (Promega) measures ADP generated in a kinase-catalyzed reaction using a coupled assay that culminates in luminescence output. While the first step entails addition of an ADP-Glo reagent that effectively terminates the kinase reaction by depleting the unreacted ATP, the second detection reagent converts the remaining ADP to ATP and allows this newly synthesized ATP to be measured using a luciferase/luciferin reaction. The measured luminescence correlates with the amount of ADP generated in the kinase assay.

For the FraD assays, $5 \mu \mathrm{L}$ of the assay was added to $5 \mu \mathrm{L}$ of the ADP-Glo reagent, and the reaction mixture incubated at $22^{\circ} \mathrm{C}$ for $1 \mathrm{~h}$. Subsequently, $10 \mu \mathrm{L}$ of the detection reagent was added and incubated at $22^{\circ} \mathrm{C}$ for $1 \mathrm{~h}$. The detection reagent was stored in dark and all steps containing this reagent were carried out in the dark. The $20-\mu \mathrm{L}$ reaction was then transferred to 384 well-white flat bottom polystyrene microplates (Greiner Bio-One) and luminescence was measured using an Infinite M1000 PRO (TECAN) plate reader [instrument settings: integration time of $1000 \mathrm{msec}$; settle time of $300 \mathrm{msec}$, and no attenuation]. Blank readings were subtracted from the test readings to obtain the final luminescence. A standard curve was generated using relative light units (RLU) versus different concentrations of ADP (0.02 to 0.6 $\mathrm{mM}$ in assay buffer), and used as a reference for calculating ADP produced due to FraD activity. Blanks for the standard curve included all the buffer components except ADP.

To determine initial velocities, time-course analyses over four time points was performed. Conditions were chosen such that $<30 \%$ of the initial substrate concentration was cleaved at the last time point. Linear regression (Excel) analysis of ADP formed as a function of time was used to calculate the initial velocity $\left(r^{2} \geq 0.96\right)$. 


\section{Results}

Determining optimal assay conditions for FraD activity: Our first goal to characterize FraD was to obtain highly purified recombinant enzyme. After overexpression in E. coli, we were able to obtain nearly homogeneous FraD using sequential immobilized metal-affinity and ion-exchange chromatography (Fig. 2A). The purified enzyme was supplemented with $10 \%$ glycerol (v/v) and stored at $-80^{\circ} \mathrm{C}$ in small aliquots. Once an aliquot was thawed for assays, it was not reused to minimize variability in activity on account of repeated freeze-thaw cycles. We observed that two cycles of freezing and thawing resulted in loss of activity for FraD up to $30 \%$ (data not shown).

Before proceeding to kinetic analyses and investigating substrate-recognition determinants, we first established the optimal $\mathrm{pH}$ and temperature for FraD activity. We used F-Asp (Behrman and Hansen 2016) to measure the FraD activity using the ADP-Glo kinase assay (see Methods). For these measurements, we performed 30-min end-point assays.

FraD kinase activity was tested at different $\mathrm{pH}$ values ranging from 4.2 to 9.8 . We used three buffers to cover this $\mathrm{pH}$ range: $\mathrm{pH} 4.2$ to 6.7 with $25 \mathrm{mM}$ Bis-Tris, $\mathrm{pH} 6.7$ to 8.8 with $25 \mathrm{mM}$ HEPES, pH 8.8 to 9.8 with $25 \mathrm{mM} \mathrm{CHES.} \mathrm{To} \mathrm{control} \mathrm{for} \mathrm{buffer-related} \mathrm{variations,} \mathrm{we} \mathrm{included}$ corrections at the overlap points by measuring activity at $\mathrm{pH} 6.7$ using both Bis-Tris and HEPES, and at pH 8.8 using HEPES and CHES. Moreover, we confirmed that the readout from the ADP-Glo kinase assay itself was largely insensitive to the $\mathrm{pH}$ range tested (data not shown). These assays were conducted twice under identical conditions and the mean relative activity of FraD was plotted versus assay pH (Fig. 2B). Because all the buffers had been prepared at $22^{\circ} \mathrm{C}$, the final plot (Fig. 2B) reflecting activity at $37^{\circ} \mathrm{C}$ includes corrections based on the $\Delta \mathrm{pKa} /{ }^{\circ} \mathrm{C}$ for each buffer. FraD activity is optimal between $\mathrm{pH} 7.3$ to 8 (Fig. 2B), with the overall plot indicating the participation of at least two titratable groups in the catalytic mechanism. 
FraD kinase activity was tested at different temperatures ranging from 4 to $80^{\circ} \mathrm{C}$. To ensure temperature accuracy, assays were performed using a PCR thermocycler (PTC-100, MJ Research, Inc.) and $0.5-\mathrm{mL}$ thin-walled tubes. These assays were conducted twice under identical conditions and the mean relative activity of FraD was plotted versus assay temperature (Fig. 2B). From this analysis, we determined the temperature optimum of $37^{\circ} \mathrm{C}$ for FraD activity.

We tested the ability of ATP, CTP, GTP and UTP to serve as the phosphoryl donor for the FraD-catalyzed reaction. The ADP-Glo assay, which is specific for measuring ADP, could not be used for this purpose. Instead, we employed a FraB + G6PDH-based coupled assay that we recently described (Sabag-Daigle et al. 2016). Results from these experiments indicated that ATP is greatly preferred over CTP, GTP or UTP (data not shown).

Michaelis-Menten analysis of FraD activity: By varying substrate concentrations 100 -fold from 0.1 - $10 \mathrm{mM}$ and using activities determined from end-point measurements, we established the anticipated saturable behavior. Michaelis-Menten curves were generated using Kaleidagraph (Synergy), and $K_{m}$ and $K_{\text {cat }}$ were determined to be $0.6 \pm 0.01 \mathrm{mM}$ and $5689 \pm 338 \mathrm{~min}^{-1}$, respectively (mean \pm standard deviation from four trials; data not shown). The curve-fit errors for $K_{m}$ and $k_{c a t}$ did not exceed $10 \%$ and $3 \%$, respectively, in these trials $\left(r^{2} \geq 0.98\right)$. Subsequently, we measured the initial velocity at different substrate concentrations, and determined $K_{m}$ and $k_{\text {cat }}$ to be $0.77 \pm 0.08 \mathrm{mM}$ and $6364 \pm 180 \mathrm{~min}^{-1}$ (Fig. 3, left; curve-fit errors are listed and $\mathrm{r}^{2}=$ $0.99)$; these parameters in turn yield a $k_{\text {cat }} / K_{\mathrm{M}}=8265 \mathrm{~min}^{-1} \mathrm{mM}^{-1}( \pm 10 \%$ error $)$.

Substrate specificity of FraD: Besides F-Asp, other Amadori compounds based upon modification in either the amino acid or sugar moiety were tested as potential FraD substrates to map the enzyme's substrate-recognition determinants. Because we expected the substrates to be recognized and catalyzed differently, we empirically determined the optimal assay conditions for each by varying the time of incubation (up to $60 \mathrm{~min}$ ) and or the concentration of FraD (from 
4 to $100 \mathrm{nM}$ ). We tested all substrates at $5 \mathrm{mM}$, nearly ten-fold greater than the $K_{m}$ that we determined for FraD-catalyzed phosphorylation of F-Asp, and determined their initial velocities. Other than fructose-L-aspartate, we tested fructose-D-aspartate, fructose-L-glutamate (F-Glu), fructose-L-asparagine (F-Asn), fructose-L-cysteic acid (F-Cysteic), tagatose-L-aspartate, xylulose-L-aspartate and ribulose-L-aspartate (Fig. 4A). Each substrate was tested thrice under identical conditions and the mean relative activity (in percent) was plotted using F-Asp as the reference (Fig. 4B).

With regard to the amino acid, FraD was able to act on the four variants that we tested (FAsp $>$ F-Glu $>$ F-Asn $>$ F-Cysteic, all tested at $5 \mathrm{mM}$ ). Surprisingly, FraD acted with equal efficiency on both F-L-Asp and F-D-Asp, reflecting an unusual capacity to accept both stereoisomers. As far as the sugar is concerned, the tolerance to change is very small. Switching fructose to tagatose, its C4 epimer, resulted in nearly complete loss of activity. Replacing the ketohexose with two ketopentoses (xylulose or ribulose) resulted in at least a 100-fold decrease in activity (Fig. 4B). Ribulose has the same chirality at carbons $3^{\prime}$ and $4^{\prime}$ carbons $4^{\prime}$ and $5^{\prime}$ in fructose while xylulose has the same chirality at carbons $3^{\prime}$ and $4^{\prime}$ as carbons $3^{\prime}$ and $4^{\prime}$ in fructose. When fructose was tested as a substrate, we did not detect any activity (data not shown).

To characterize the preference of FraD for F-L-Asp versus F-D-Asp, we performed Michaelis-Menten analysis with the latter. Using activities determined from end-point measurements with 0.1 to $10 \mathrm{mM}$ F-D-Asp, $K_{m}$ and $k_{\text {cat }}$ were determined to be $1 \pm 0.05 \mathrm{mM}$ and $6508 \pm 585 \mathrm{~min}^{-1}$, respectively (mean \pm standard deviation from three trials; data not shown). The curve-fit errors for $K_{m}$ and $k_{\text {cat }}$ did not exceed $11 \%$ and $4 \%$, respectively, in these trials $\left(r^{2} \geq\right.$ 0.98). Using initial velocity measurements in a separate exercise, we determined $K_{m}$ and $k_{c a t}$ to be $0.94 \pm 0.07 \mathrm{mM}$ and $6380 \pm 144 \mathrm{~min}^{-1}$ (Fig. 3, right; curve-fit errors are listed and $\mathrm{r}^{2}=0.99$ ); these parameters in turn yield a $k_{\text {cat }} / K_{\mathrm{M}}=6787 \mathrm{~min}^{-1} \mathrm{mM}^{-1}( \pm 10 \%$ error). 


\section{Discussion}

Although a three-step conversion was proposed for the catabolism of F-Asn (Fig. 1), there had been no biochemical characterization of the enzymes that catalyze these steps. Here, we demonstrate that FraD, the second enzyme in this pathway, indeed transforms F-Asp to 6-P-FAsp. Our results are consistent with findings from a recent study where elimination of the FraB deglycase activity led to an accumulation of 6-P-F-Asp in Salmonella, suggesting that a kinase acts upstream of the deglycase (Sabag-Daigle et al. 2016). As the build-up of 6-P-F-Asp was shown to be associated with toxicity to Salmonella (Sabag-Daigle et al. 2016), it is important to understand the catalytic properties of this kinase.

Because the functional roles for the structural genes in the fra locus were predicted based on the E. coli frl operon that permits utilization of F-Lys (Wiame et al. 2002), it is instructive to compare the kinetic parameters of Salmonella FraD and E. coli FrID, which converts F-Lys to 6P-F-Lys. FrID exhibits a $k_{\text {cat }} / K_{\mathrm{M}}=45,000 \mathrm{~min}^{-1} \mathrm{mM}^{-1}$ (Wiame et al. 2004; also, see Kojima et al. 2013), nearly five-fold greater than the $8265 \mathrm{~min}^{-1} \mathrm{mM}^{-1}$ that we determined for FraD (Fig. 3). YurL, the FrID homolog in Bacillus subtilis, phosphorylates F-Lys with a $k_{\text {cat }} / K_{\mathrm{M}}=15 \mathrm{~min}^{-1} \mathrm{mM}^{-1}$ (Wiame et al. 2004). It is not possible to correlate these catalytic efficiencies with metabolic capabilities and fitness payoffs, especially since the activity reported for FrID and YurL utilized $\varepsilon^{-}$ glycated lysine as opposed to the $\alpha$-glycated F-Asp that we used to study FraD.

Even though FraD, FrID and YurL differ with respect to primary amino acid sequence, substrate specificity, and catalytic efficiency, they share the common task of phosphorylating fructose-amines for subsequent bacterial catabolism (Deppe et al. 2011; Wiame et al. 2004). Both YurL and FrID are known to phosphorylate a variety of fructose-amines (Wiame et al. 2004), mirroring our findings with FraD (Fig. 4). YurL preferred F-Val > F-Gly >> F-Lys $(\varepsilon-$ glycated) (Wiame et al 2004), but FrID exhibited the opposite trend: F-Lys ( $\varepsilon$-glycated) >> F-Gly 
$>$ F-Val. We observed that FraD prefers F-Asp > F-Glu > F-Asn > F-Cysteic (all of them $\alpha$ glycated). Overall, YurL, FrID and FraD exhibit preferences for hydrophobic, basic and acidic amino acid residues that are linked to fructose.

When we examined the importance of the sugar in facilitating substrate recognition by FraD, it became evident that few changes are tolerated. Substitution of fructose in F-Asp with its C4 epimer led to nearly complete loss of activity, as was the replacement of fructose (a ketohexose) with xylulose or ribulose (ketopentoses; Fig. 4B). Similar studies with sugar analogues were not performed with FrID/YurL, but FrID (like FraD) also did not accept fructose as a substrate (Wiame et al. 2002; see Conway and Voglmeir, 2016 for a review of sugar kinases).

Since biocatalysts are generally highly stereospecific, it was surprising that FraD would act with nearly equal efficiency with F-L-Asp and F-D-Asp (Fig. 3). There are a few precedents of enzymes that fail to display strict chiral preferences (Calendar and Berg 1967; Nardi-Dei et al. 1997; Villiers and Hollfelder 2009). For example, B. subtilis tyrosyl-tRNA synthetase activates both D- and L-tyrosine, although there appears to be kinetic discrimination; the $K_{\mathrm{M}}$ for the D-Tyr is four-fold lower than the L-Tyr, and the $k_{\text {cat }}$ for L-Tyr is 83-fold higher than D-Tyr (Calendar and Berg 1967). In the case of the adenylation domain of tyrocidine synthetase (TycA), the enzyme displayed only a two-fold stereoselectivity for L-Phe compared to D-Phe (Villiers and Hollfelder 2009). The ability of FraD to act on F-L-Asp and F-D-Asp with nearly equal $k_{\text {cat }} / K_{m}$ (Fig. 3) mirrors TycA. Overall, these instances probably reflect the innate adaptive landscape of enzymes that fosters selective growth advantages under specific conditions (Khersonsky and Tawfik 2010), a testable premise. Importantly, our findings suggest that while FraD is rigid with respect to recognition determinants in the sugar moiety, it is flexible with regard to the amino acid (Fig. 4). We hope that ongoing crystallographic studies of FraD will provide a clear picture of the latitude with respect to anchoring of the amino acid even while allowing an optimal 
alignment of the active-site residues for phosphorylation of the $\mathrm{C} 6-\mathrm{OH}$ group in F-Asp. FraD joins the small family of enzymes that breach the expectation of exquisite stereospecificity during macromolecular recognition.

\section{Acknowledgements}

We are grateful to Jikang Wu [laboratory of Dr. Vicki Wysocki, Ohio State University (OSU)] for his kind assistance with mass spectrometry, which was used to ascertain the bona fides of the various Amadori products, Alex Bogard (OSU) for help with syntheses, Drs. Anice Sabag-Daigle and Brian Ahmer (OSU) for providing the FraD overexpression clone, Drs. Dmitri Kudryashov and Jennifer Ottesen (OSU) for generous consent to use their TECAN plate reader and MALDIToF, respectively, and Dr. Ahmer for comments on the manuscript. This work was supported by the National Institutes of Health (R01-Al116119 to EJB and VG). 


\section{REFERENCES}

Ali, M. M., Newsom, D. L., Gonzalez, J. F., Sabag-Daigle, A., Stahl, C., Steidley, B., Dubena, J., Dyszel, J. L., Smith, J. N., Dieye, Y., Arsenescu, R., Boyaka, P. N., Krakowka, S., Romeo, T., Behrman, E. J., White, P. and Ahmer, B. M. M. 2014. Fructose-Asparagine Is a primary nutrient during growth of Salmonella in the inflamed intestine. PLoS Pathog. 10, e1004209.

Anet, E. F. L. J. 1957. Chemistry of non-enzymic browning. II. Some crystalline amino aciddeoxy-sugars. Austr. J. Chem. 10, 193-197.

Anet, E. F. L. J. and Reynolds, T. M. 1957. Chemistry of non-enzymic browning. II. Reactions between amino acids, organic acids, and sugars in freeze-dried apricots and peaches. Aust. J. Chem. 10, 182-191.

Calendar, R. and Berg, P. 1967. D-Tyrosyl RNA: Formation, hydrolysis and utilization for protein synthesis. J. Mol. Biol. 26, 39-54.

Conway, L. P. and Voglmeir, J. 2016. Functional analysis of anomeric sugar kinases. Carbohyd. Res. 432, 23-30.

Deppe, V. M., Klatte, S., Bongaerts, J., Maurer, K-H., O’Connell, T. and Meinhardt, F. 2011. Genetic control of Amadori product degradation in Bacillus subtilis via regulation of frIBONMD expression by FrIR. Appl. Env. Microbiol. 77, 2839-2846.

Eichner, K., Reutter, M. and Wittmann, R. 1994. Detection of Amadori compounds in heated foods. ACS Symposium Series (USA) 543, 42-54.

Hansen, A. L. and Behrman, E. J. 2016. Synthesis of 6-phosphofructose aspartic acid and some related Amadori compounds. Carbohyd. Res. 431, 1-5.

Katchalsky, A. and Sharon, N. 1953. Kinetics of aldose-amino acid interaction. Biochim. Biophys. Acta. 10, 290-301. 
Khersonsky, O. and Tawfik, D. S. 2010. Enzyme promiscuity: A mechanistic and evolutionary pespective. Ann. Rev. Biochem. 79, 471-505.

Kojima, K., Mikami-Sakaguchi, A., Kameya, M., Miyamoto, Y., Ferri, S., Tsugawa, W. and Sode, K. 2013. substrate specificity engineering of Escherichia coli derived fructosamine 6-kinase. Biotechnol. Lett. 35, 253-258.

Laroque, D., Inisan, C., Berger, C., Vouland, E., Dufossé, L. and Guérard, F. 2008. Kinetic study on the Maillard reaction. Consideration of sugar reactivity. Food Chem. 111, 1032-1042.

Maillard, L. -C. 1912. Action des acides aminés sur les sucres. C. R. Hebd. Séances Acad. Sci. 154, 66-68.

Mossine, V. V., Glinsky, G. V. and Feather, M. S. 1994. The preparation and characterization of some Amadori compounds (1-amino-1-deoxy-D-fructose derivatives) derived from a series of aliphatic $\omega$-amino acids. Carbohydr. Res. 262, 257-270.

Mossine, V. V. and Mawhinney, T. P. 2010. 1-Amino-1-Deoxy-D-Fructose ("Fructosamine") and its derivatives. Adv. Carbohyd. Chem. Biochem. 64, 291-402.

Nardi-Dei, V., Kurihara, T., Park, C., Esaki, N. and Soda, K. 1997. Bacterial DL-2-haloacid dehalogenase from Psedomonas sp.113; gene cloning and structural comparison with D- and L-2 haloacid dehalogenases. J. Bacteriol. 179, 4232-4238.

Pardo, C., Alkorta, I. and Elguero, J. 2006. A DFT study of the geometric, magnetic NMR chemical shifts and optical rotation properties of Trögers bases. Tetrahedron: Asymmetry, 17, 191-196.

Sabag-Daigle, A., Blunk, H. M., Sengupta, A., Wu, J., Bogard, A. J., Ali, M. M., Stahl, C., Wysocki, V. H., Gopalan, V., Behrman, E. J. and Ahmer, B.M.M. 2016. A metabolic 
intermediate of the fructose-asparagine utilization pathway inhibits growth of Salmonella enterica fraB mutant. Sci. Rep. 6, 28117; doi: 10.1038/srep28117.

Sun, Y. X., Hayakawa, S., Chuamanochan, M., Fujimoto, M., Innun, A. and Izumori, K. 2006. Antioxidant effects of Maillard reaction products obtained from ovalbumin and different Daldohexoses. Biosci. Biotech. Biochem. 70, 598-605.

Tropea, J. E., Cherry, S. and Waugh, D. S. 2009. Expression and purification of soluble His(6)tagged TEV protease. Methods Mol. Biol. 498, 297-307.

Villiers, B. R. M. and Hollfelder, F. 2009. Mapping the limits of substrate specificity of the adenylation domain of TycA. ChemBiochem. 10, 671-682.

Walton, D. J., McPherson, J. D., Hvidt,T. and Szarek, W. A. 1987. Synthetic routes to N-(1deoxy-d-fructos-1-yl)amino acids by way of reductive amination of hexos-2-uloses. Carbohydr. Res. 167, 123-130.

Wiame, E., Delpierre, G., Collard, F. and Van Schaftingen, E. 2002. Identification of a pathway for the utilization of the Amadori product fructose-lysine in Escherichia coli. J. Biol. Chem. 277, 42523-42529.

Wiame, E., Duquenne, A., Delpierre, G. and Van Schaftingen, E. 2004. Identification of enzymes that act on $\alpha$-glycated amino acids. FEBS Lett. 577, 469-472.

\section{Figure legends}

Figure 1. Proposed pathway for fructose-asparagine utilization in Salmonella enterica. 
Figure 2. Purity of recombinant Salmonella FraD and determination of optimal conditions for its activity. (A) SDS-PAGE [12\% (w/v) polyacrylamide] analysis of the final FraD preparation obtained after overexpression in E. coli and a two-column purification. Lane 1, size markers; lane 2, $10 \mu \mathrm{g}$ of the final preparation of FraD. (B) Assay $\mathrm{pH}$ (left) and temperature (right) were varied to determine the optimum for each variable. Standard assays conditions (10 nM FraD, $0.8 \mathrm{mM}$ F-Asp, $30 \mathrm{~min}$ at $37^{\circ} \mathrm{C}$ ) were employed to obtain these measurements. The relative activity of $\mathrm{FraD}$ was calculated at the different $\mathrm{pH}$ and temperatures using as reference the condition at which maximum activity was observed. The mean values were calculated using results from two independent experiments.

Figure 3. Michaelis-Menten analysis of recombinant FraD with F-L-Asp (left) and F-D-Asp (right). The $k_{c a t}$ and $K_{m}$ values together with their respective curve-fit errors are listed (see text for additional supporting data).

Figure 4. Substrate specificity of FraD. (A) Structures of the different substrate analogues tested. (B) Relative activity (\%) of each substrate analogue was calculated using as reference the initial velocity observed with F-L-Asp. All substrates (at $5 \mathrm{mM}$ ) were tested under standard assay conditions $\left(\mathrm{pH} 7.5,37^{\circ} \mathrm{C}\right)$ to determine their respective initial velocity. Mean \pm standard deviation values were calculated from three independent experiments.

\section{Figure 1}




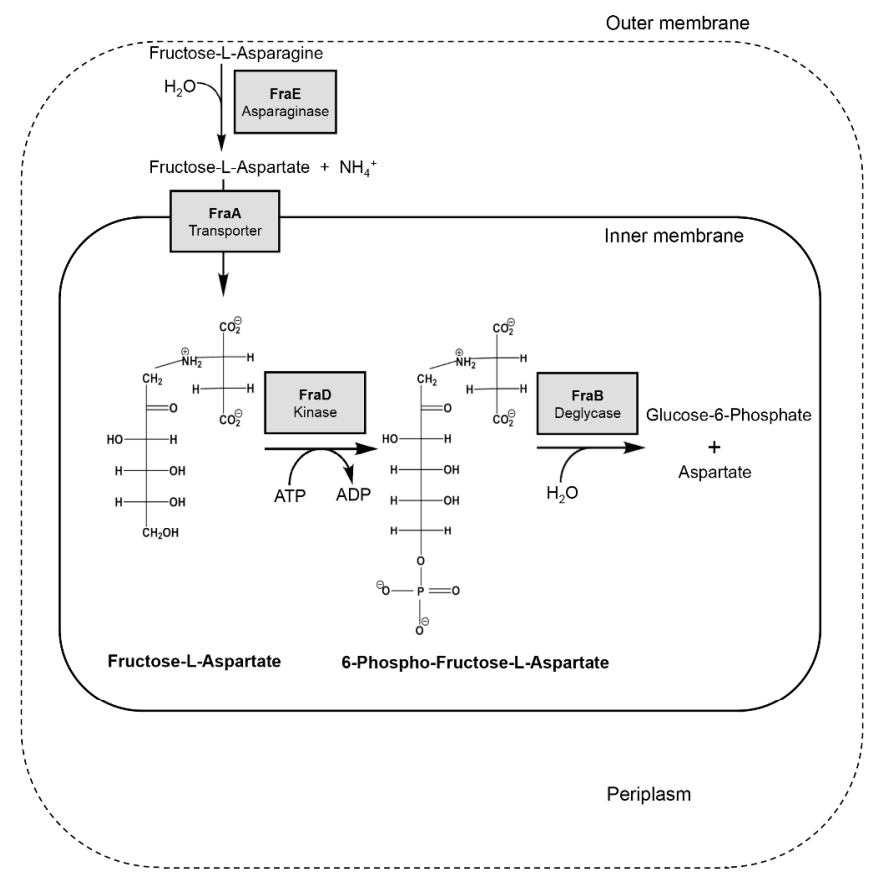


Figure 2
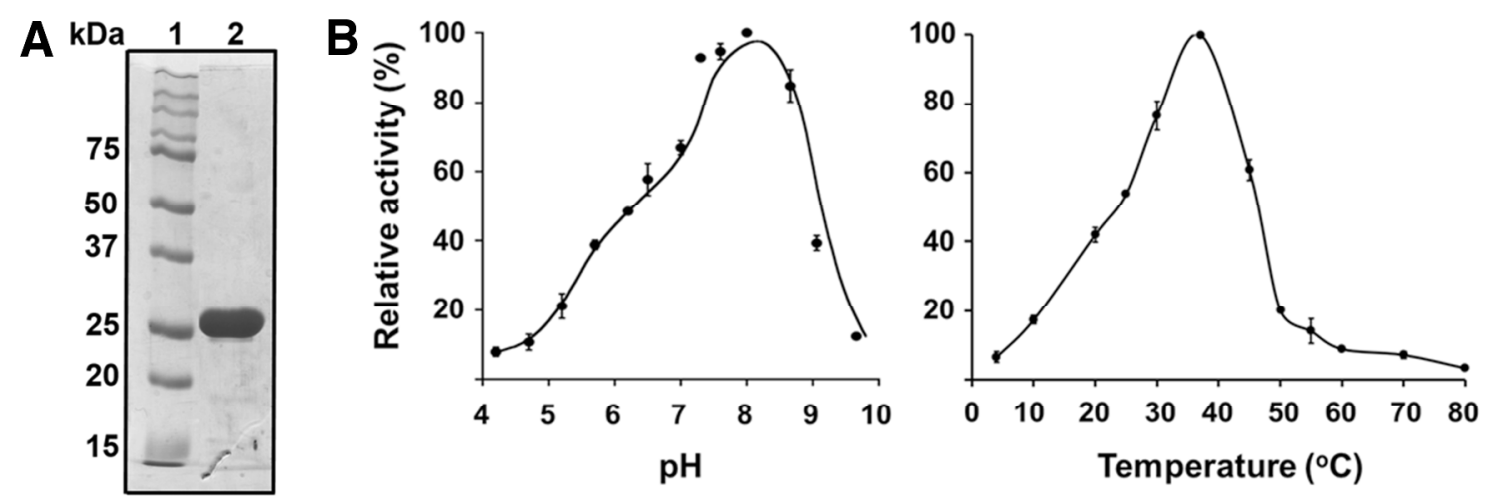
Figure 3
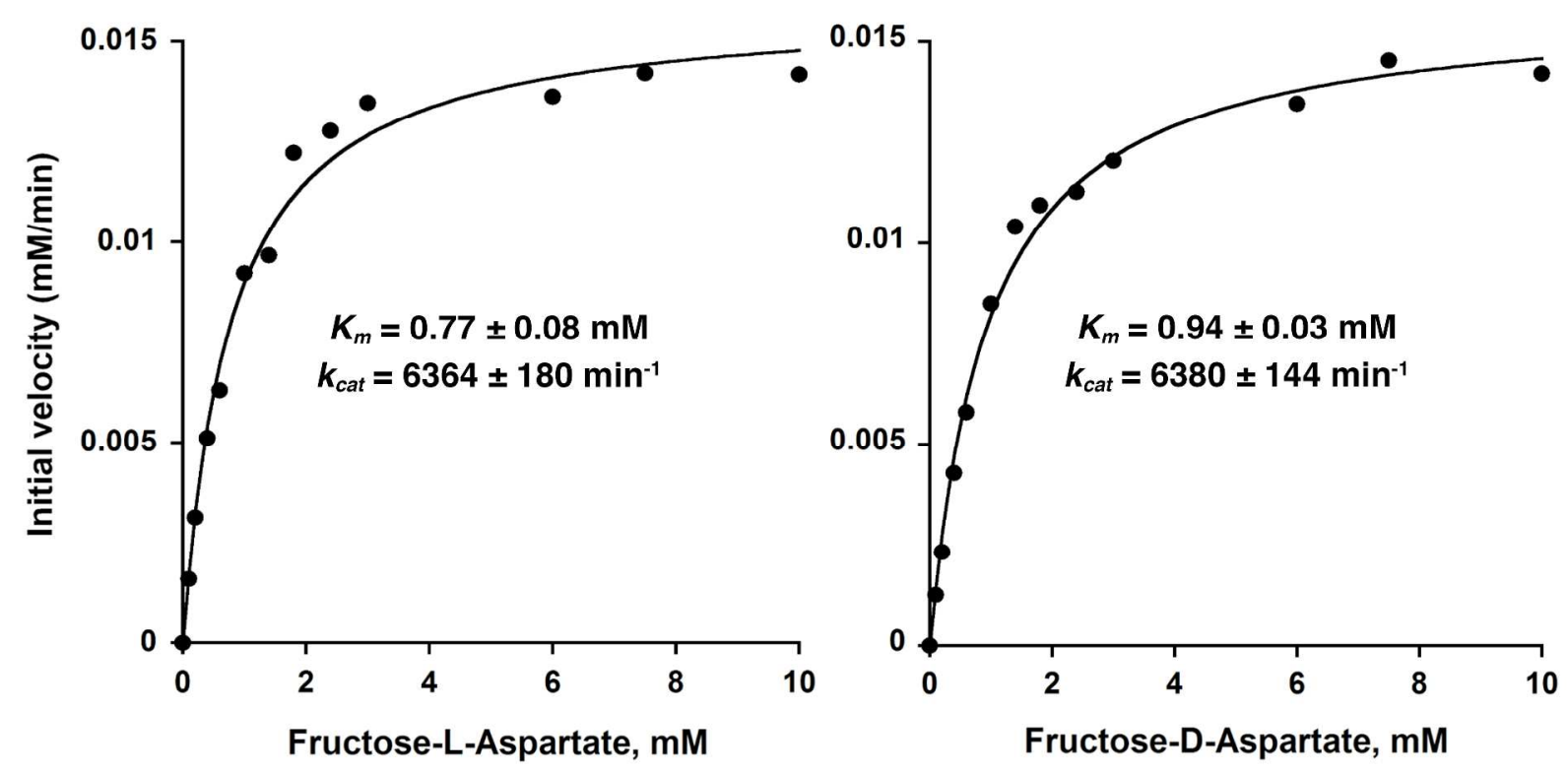

https://mc06.manuscriptcentral.com/bcb-pubs 


\section{Figure 4}

A
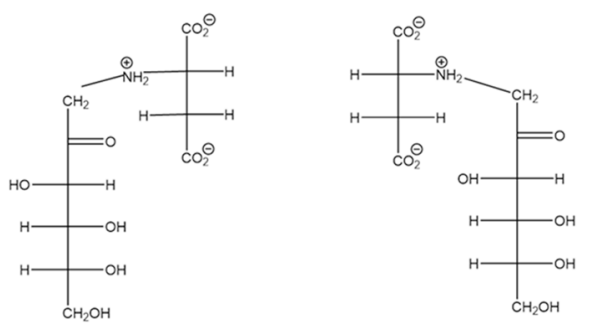

Fructose-L-Aspartate

Fructose-D-Aspartate

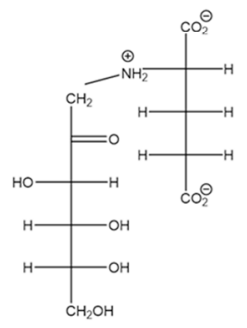

Fructose-L-Glutamate

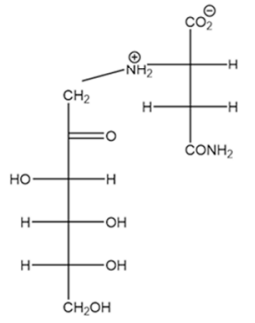

Fructose-L-Asparagine

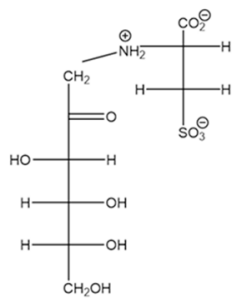

Fructose-L-Cysteic Acid

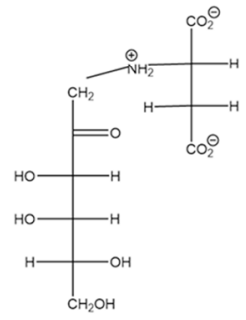

Tagatose-L-Aspartate
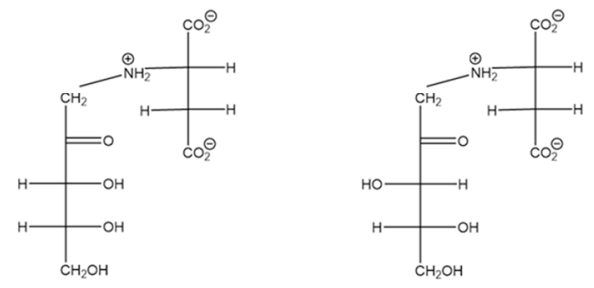

Ribulose-L-Aspartate

Xylulose-L-Aspartate

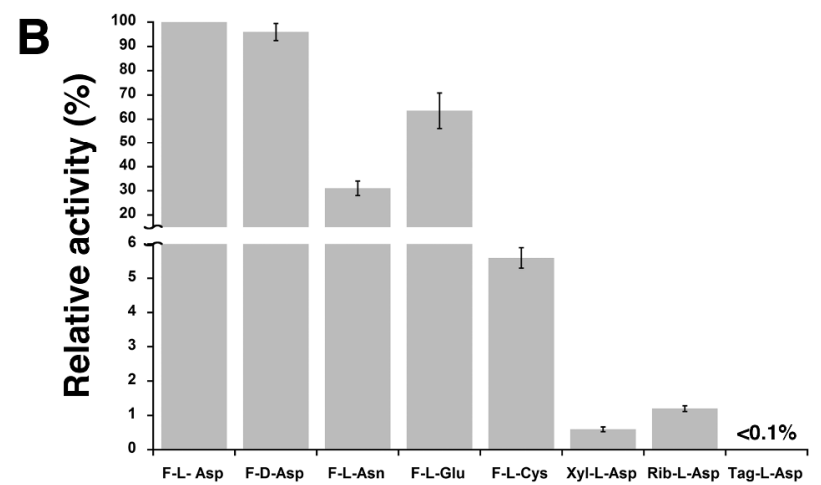

Substrates 